\title{
KINETICS OF THE CATHODIC DISCHARGE OF AMMONIUM ION DISSOLVED IN DIMETHYLSULFOXIDE ON PLATINUM
}

\author{
C. Martínez, A. J. Arvía and J. A. Wargon \\ Instituto de Investigaciones Fisicoquímicas Teóricas y Aplicadas, División Electroquímica, Facultad de \\ Ciencias Exactas, Universidad Nacional de La Plata, La Plata, Argentina
}

(Revised version received 4 December 1972)

\begin{abstract}
The cathodic discharge of ammonium ion dissolved in DMSO solution on platinum electrodes in the temperature range from 25 to $44^{\circ} \mathrm{C}$ yields ammonia and hydrogen at the ratio $2: 1$. The kinetics of the reaction was studied both under stationary and non-stationary conditions and reveals an influence of the treatment of the electrode surface. The kinetic parameters were interpreted with a reaction mechanism involving the participation of adsorption competition between either solvent or impurity molecules and hydrogen atoms, assuming the recombination of these adatoms is rate determining.
\end{abstract}

\section{INTRODUCTION}

An important problem to be solved in electrochemical kinetics concerns the participation of the solvent in the mechanism of the electrode reactions [1-4]. To face the problem it is worthwhile to study a particular electrode reaction in different solvents.

This work refers to the discharge of the ammonium ion and other related electrochemical reactions using platinum electrodes and dimethylsulfoxide (DMSO) as solvent. As is known[5], the solubility of ammonium salts in this solvent is great and solutions behave as those of strong clectrolytes. Therefore, it is possible to study the electrochemistry of ammonium salt solutions in DMSO from the kinetic viewpoint.

Several questions may be answered by studying this reaction. Firstly it would be possible to ascertain if the ammonium radical is formed as a reaction intermediate of the cathodic reaction. Secondly, it is likely that hydrogen atoms participate in the process, these atoms behaving similarly as those directly yielded by the electrochemical reduction of the solvated hydrogen ion. The different reaction products of the ammonium ion discharged together with the solvent may contribute to adsorption processes on the electrode, thus affecting the kinetics of the reaction.

\section{EXPERIMENTAL}

Commercial DMSO (BDH, Baker or Fluka) contained water as major impurity $(0.03 \%)$ and other less volatile substances. The solvent, after being kept in contact with activated alumina, was distilled several times under nitrogen. The first distillation was made at $32-35^{\circ} \mathrm{C}$ under a reduced pressure and the second was made on calcium hydride[5,6]. Potassium per- chlorate (Carlo Erba p.a.) vacuum dried at $120-150^{\circ} \mathrm{C}$, and ammonium nitrate (Riedel de Häen $A-G$ ) vacuum dried at $55-60^{\circ} \mathrm{C}$, were used.

Solutions were prepared under nitrogen and the solvent being directly distilled into calibrated flasks containing previously weighed salts. The electrolytic solutions were always handled under nitrogen. Ammonium nitrate $(0.004-0.025 \mathrm{M})$ dissolved in $1 \mathrm{M}$ potassium perchlorate and concentrated solutions of ammonium nitrate $(1.0-20 \mathrm{M})$ werc used. Viscosity measurements were made with a Cannon-Fenske pipette. Densities were determined by picnometry.

Experiments with rotating disk electrodes under stationary and nonstationary conditions were made. Static electrodes were also used in chronopotentiometry, cyclic voltammetry and conventional stationary measurements, within the temperatures range between 25 and $44^{\circ} \mathrm{C}$. Details about cell mounting and the rotating device are given in earlier publications [7]. The platinum rotating disk electrode area was $0.07 \mathrm{~cm}^{2}$. This surface was mirror polished with alumina of different grain sizes. The counterelectrode was a platinum sheet with an area about 500 times larger than that of the working electrode.

A conventional cell was used in chronopotentiometry with a platinum working electrode $\left(0.129 \mathrm{~cm}^{2}\right)$ embedded into a Teflon ${ }^{\circledR}$ bar. The same cell was used in the cyclic voltammetry experiments. The corresponding electronic circuitry was described in another work [8].

Decay of the electrode potential when electrolysis was interrupted as well as potential buildup under galvanostatic conditions were recorded. Two reference electrodes were mainly used: (i) $\mathrm{Ag} / \mathrm{Ag}^{+}$(DMSO); (ii) aqueous saturated calomel. To go from reference (i) to reference (ii) $0.400 \mathrm{~V}$ should be added to the potential reading. 
RESULTS

\section{Preliminary experiments}

A $1 \boldsymbol{M}$ ammonium nitrate solution was potentiostatically electrolysed in a conventional cell with bright platinum electrodes using an $\mathrm{Ag} / \mathrm{AgCl} / \mathrm{Cl}^{-}$ (DMSO) reference electrode. A stable rest potential was attained neither before nor after the electrolysis. Up to $0.6 \mathrm{~V}$ more cathodic than the rest potential the current was less than 1-2 $\mu A$. At a more negative potential the current initially increased but after some time it decreased, finally attaining a constant value after $30 \mathrm{~min}$.

At a current larger than $100 \mu \mathrm{A} / \mathrm{cm}^{2}$ hydrogen and ammonia were formed. The latter was identified both in the gas phase and in the bulk of the solution. Small quantities of dimethylsulphide and still smaller quantities of some other unknown compound were detected. After $24 \mathrm{~h}$ electrolysis at ca $100 \mu \mathrm{A} / \mathrm{cm}^{2}$, the solution in the cathodic compartment acquired a yellowish tinge.

\section{Current efficiency}

The yields were calculated on the basis that the total cathodic reaction is $\mathrm{NH}_{4}^{+}+e=\mathrm{NH}_{3}+1 / 2 \mathrm{H}_{2}$. The current efficiency for the hydrogen formation was near to $100 \%$. The current efficiency for ammonia was less than $100 \%$ when evaluated from gaseous samples obtained by nitrogen bubbling through the solution because of the high solubility of ammonia in DMSO [6], but when dissolved ammonia was evaluated, the current efficiency was also very close to $100 \%$.

\section{Current-potential curves obtained with the rotating disk} electrode

Figure 1 shows three potentiostatic polarization curves obtained with recently polished electrodes, reading the current at different prefixed times after the application of the potential signal. Curves obtained with increasing and decreasing cathodic polarization exhibit a marked hysteresis. There is however a reproducible limiting current, if current readings were shorter than $2 \mathrm{~min}$ after the potential was applied. Figure 2 shows polarization curves obtained with current reading $30 \mathrm{~s}$ after potential was applied. At any rate the limiting current increases linearly with the square root of the rotating speed and with the ammonium nitrate concentration (Figs. 3 and 4).

Figures 5 and 6 are Arrhenius plots for the cathodic limiting current and the experimental diffusion coefficient calculated with Newman's equation[9], respectively. The experimental activation energy for the total transport process is $3.65 \pm 0.15 \mathrm{kcal} / \mathrm{mole}$; the activation energy for viscous flow is $4.03 \pm 0.02$ $\mathrm{kcal} / \mathrm{mole}$, and the activation energy for diffusion is $4.62 \pm 0.10 \mathrm{kcal} / \mathrm{mole}$. The theoretical activation energy calculated from the activation energies of viscous flow and diffusion, according to Levich equation[9], is $3.75 \pm 0.10 \mathrm{kcal} / \mathrm{mole}$, in good coincidence with the experimental value.

\section{Chronopotentiometry}

Figure 7 shows a typical potential/time display at constant current. During the cathodic current pulse $(30-90 \mu \mathrm{A})$ only one transition time is observed, $\tau_{c}$, while during the anodic pulse two transition times appear $\tau_{a}$ and $\tau_{a}^{\prime}$, being $\tau_{a}>\tau_{a}^{\prime}$. Transition times were determined according to Delahay[10]. Both $\tau_{a}$ are observed although the anodic pulse is applied before $\tau_{c}$ has been completed. The product $I \tau_{c}{ }^{1 / 2}$ is reasonably constant $\left(244 \pm 3 \mu \mathrm{A} \times \mathrm{s}^{1 / 2}\right.$ at $25^{\circ} \mathrm{C}$ and $324 \pm 4$ $\mu \mathrm{A} \times \mathrm{s}^{1 / 2}$ at $44^{\circ} \mathrm{C}$ ) and independent of the working conditions. The diffusion coefficients derived from chronopotentiometry are coincident with those determined from the rotating disk electrode data.

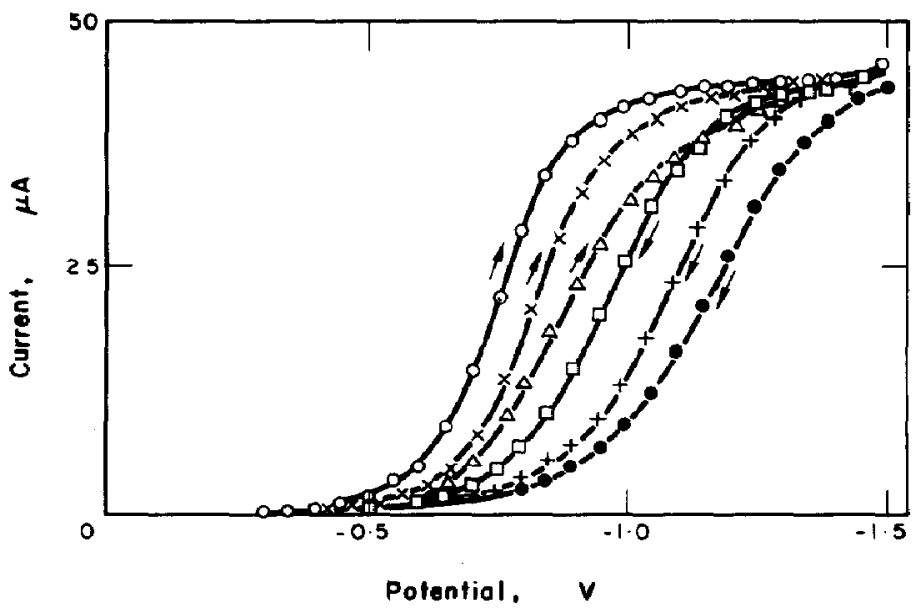

Fig. 1. Cathodic current-potential curves (potentiostatic). Pt rotating disk electrode $\left(0-07 \mathrm{~cm}^{2}\right)$ at $450 \mathrm{rpm} .0 \cdot 0045 \mathrm{M} \mathrm{NH}_{4} \mathrm{NO}_{3}+$ supporting electrolyte, $30^{\circ} \mathrm{C}$. Reference: $\mathrm{Ag} / \mathrm{AgCl} / \mathrm{Cl}^{-}$(DMSO). Current readings at $30 \mathrm{~s}(\mathrm{O}, \square) ; 1 \mathrm{~m}(x,+) ; 2 \mathrm{~m}(\Delta, O)$. Arrows indicate direction of applied potential. 


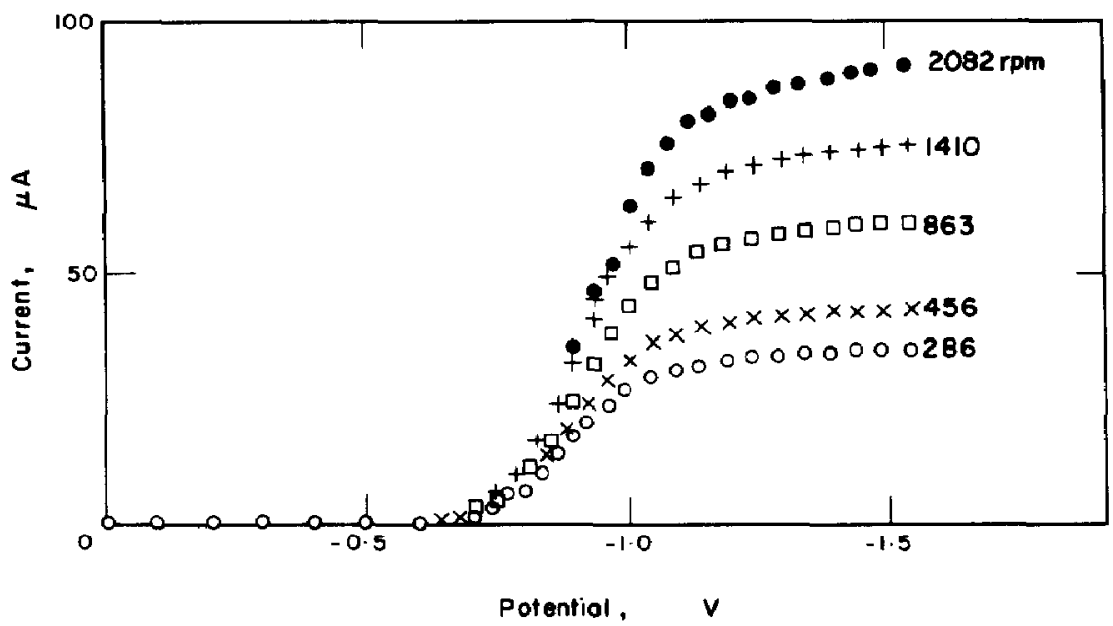

Fig. 2. Cathodic current-potential curves (potentiostatic). Pt rotating disk electrode at different rotation speeds; $0.004 M \mathrm{NH}_{4} \mathrm{NO}_{3}+$ supporting electrolyte, $30^{\circ} \mathrm{C}$. Reference: $\mathrm{Ag} / \mathrm{AgCl} / \mathrm{Cl}^{-}(\mathrm{DMSO})$. Current readings at $30 \mathrm{~s}$.

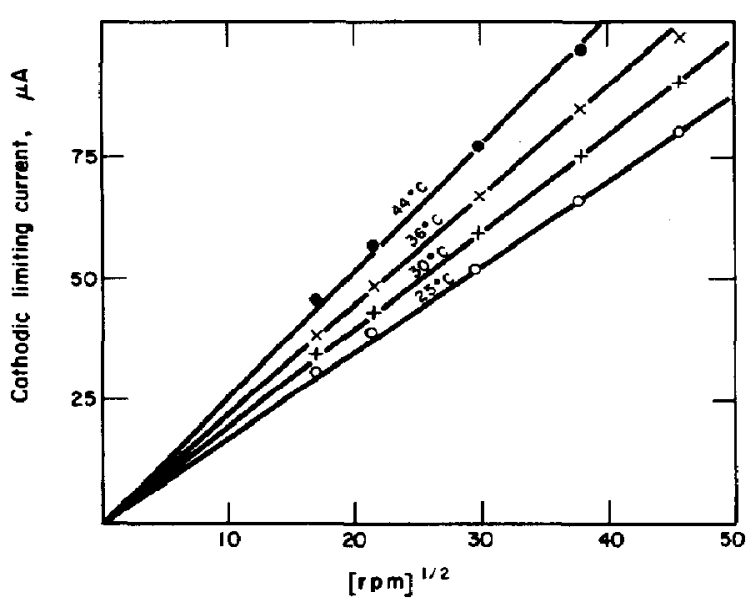

Fig. 3. Dependence of the cathodic limiting current on the square root of the rotation speed; $0 \cdot 004 \mathrm{M} \mathrm{NH}_{4} \mathrm{NO}_{3}+$ supporting electrolyte at different temperatures.

\section{Cyclic voltammetry}

Figures 8 and 9 show current-potential curves recorded between 0.2 and $-1.35 \mathrm{~V}$ and between 0.6 and $-1.35 \mathrm{~V}$ at potential sweep rates between 5 and $120 \mathrm{mV} / \mathrm{s}$. The numbers in the curves correspond to the order of the runs. A cathodic current peak is found between -1.0 and $-1 \cdot 15 \mathrm{~V}$. Its location depends mainly on the potential sweep rate and temperature. $A$ wide anodic current peak between -0.70 and $-0.68 \mathrm{~V}$ appears in the anodic halfcycle. This peak is not well defined at low potential sweep rates and low ammonium ion concentration. Instead, at higher ones, a net anodic current region is observed which corresponds to the superposition of at least two current maxima. At $44^{\circ} \mathrm{C}$, the anodic current peak at more positive potentials predominates, while at lower temperatures the prevailing current peak is the anodic one located at more negative potentials. After these current maxima in the direction of the anodic potentials a residual current exists which approaches

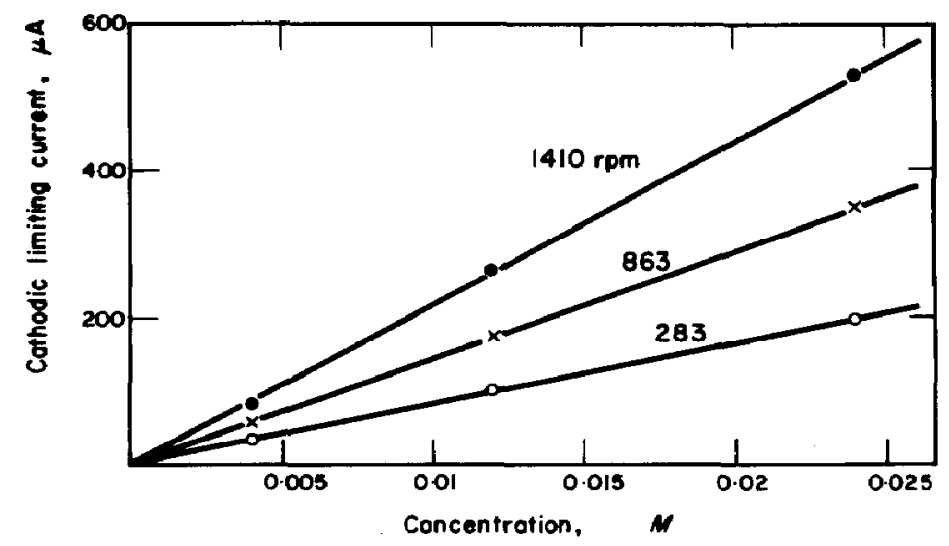

Fig. 4. Dependence of the cathodic limiting current on ammonium nitrate concentration at different rotation speeds and $25^{\circ} \mathrm{C}$. 


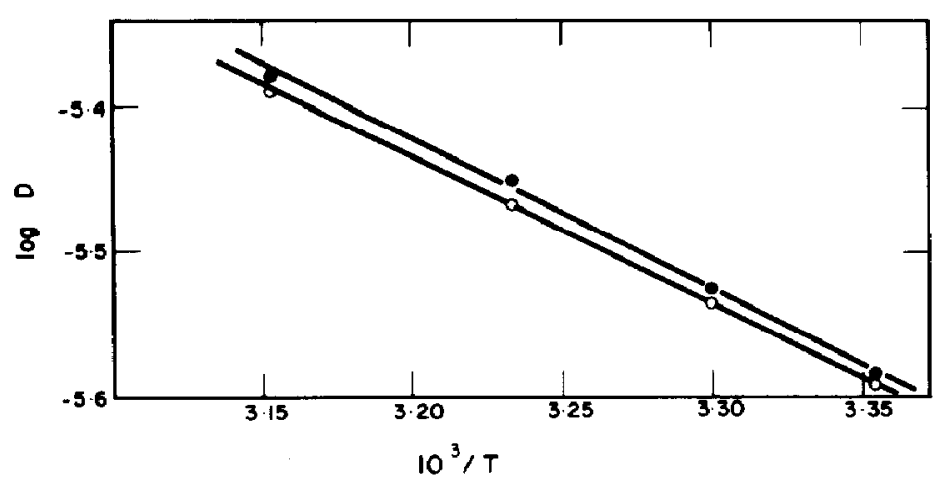

Fig. 5. Arrhenius plot for the diffusion coefficient calculated from Levich $(O)$ and Newman $(O)$ equations. $0-004 \mathrm{M} \mathrm{NH}_{4} \mathrm{NO}_{3}+$ supporting electrolyte.

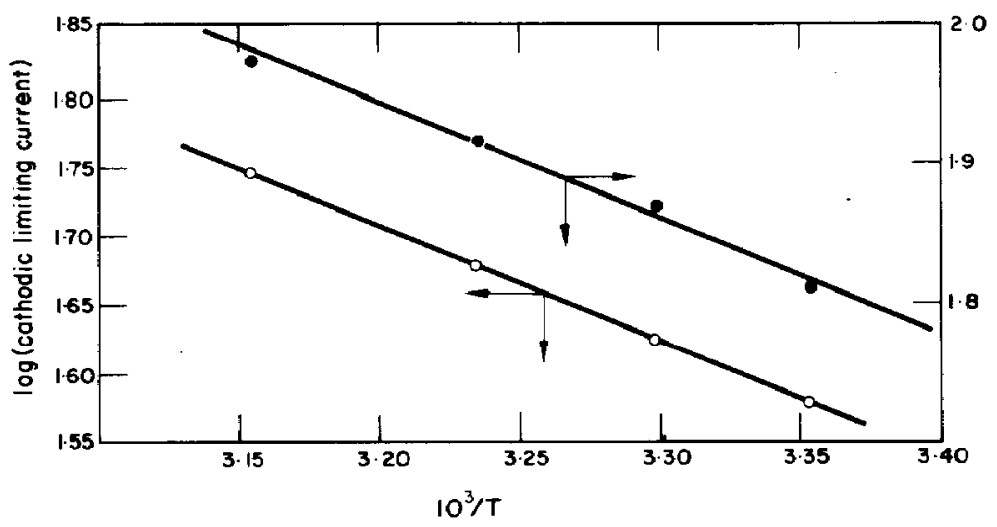

Fig. 6. Arrhenius plot for the cathodic limiting current read at 455 rpm (O) and $1410 \mathrm{rpm}$ (O). $0.004 \mathrm{M} \mathrm{NH}_{4} \mathrm{NO}_{3}+$ supporting electrolyte.

another anodic current peak at about $0.6 \mathrm{~V}$. The height of the cathodic current peak changes linearly with the square root of the potential sweep rate, $v$, although at potential sweep rates higher than $80 \mathrm{mV} / \mathrm{s}$ the linear relationship is no longer held (Fig. 10).

Current/potential records obtained hy means of repetitive cyclic voltammetry show a decrease of the height of the cathodic current peak during the successive cycles (of the order $20 \%$ at the fifth cyclic sweep). On the other hand, the height of the anodic current peak changes a little, but it shifts towards more anodic potentials with the successive cycles.

Figure 11 shows some experiments within a potential sweep amplitude from $1.0 \mathrm{~V}$ to $-1.4 \mathrm{~V}$. The anodic half cycle shows a third peak at $0.3 \mathrm{~V}$ thereabouts. The current which appears beyond $0.9 \mathrm{~V}$ is caused by the supporting electrolyte. The residual current in the potential region where the current peaks are defined in less than $5 \mu \mathrm{A}$.

\section{Influence of the nature of the electrode surface}

Voltagrams obtained with gold electrodes exhibit instead of the cathodic current peak already mentioned on platinum two overlapping cathodic current peaks (Fig. 12). No anodic current peak such as those de- scribed with platinum electrodes are found on gold electrode. There is only one anodic peak at about $0.8 \mathrm{~V}$.

\section{Influence of the reaction products}

Voltagrams of solutions containing the supporting electrolyte and high concentration of ammonia under hydrogen gas saturation were recorded. Figure 13 shows one of those voltagram covering a potential sweep amplitude from -0.4 up to $1.95 \mathrm{~V}$, at $100 \mathrm{mV} / \mathrm{s}$. The voltagram of one of these solutions washed up with nitrogen during $30 \mathrm{~min}$ prior to electrolysis, shows in the anodic and cathodic potential region the already described features for the solutions where ammonia was absent. On the other hand, the voltagram obtained by sweeping the potential from -0.4 up to $0.975 \mathrm{~V}$ after resting $10 \mathrm{~min}$ from the previous electrolysis, shows a wide anodic current peak at negative potentials. During the cathodic halfcycle, extending up to $-1.975 \mathrm{~V}$ there is a cathodic current peak related to the discharge of the ammonium ion, although somewhat increased in respect to that of the previous record. At cathodic potentials lower than that corresponding to the discharge of the ammonium ion, a small cathodic limiting 


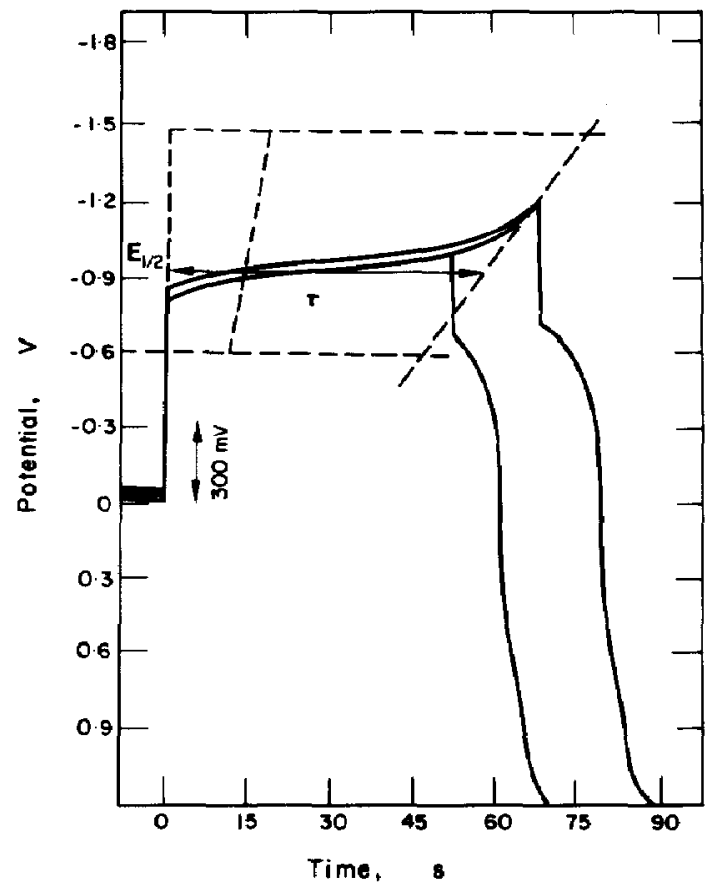

Fig. 7. Potential/time curve with an initial constant cathodic current $(43 \mu \mathrm{A})$ pulse followed by a constant anodic current pulse; $0 \cdot 0128 \mathrm{M} \mathrm{NH} \mathrm{NHO}_{3}+$ supporting electrolyte. Reference: sce $\mathrm{Pt}$ electrode area $0.13 \mathrm{~cm}^{2}$.

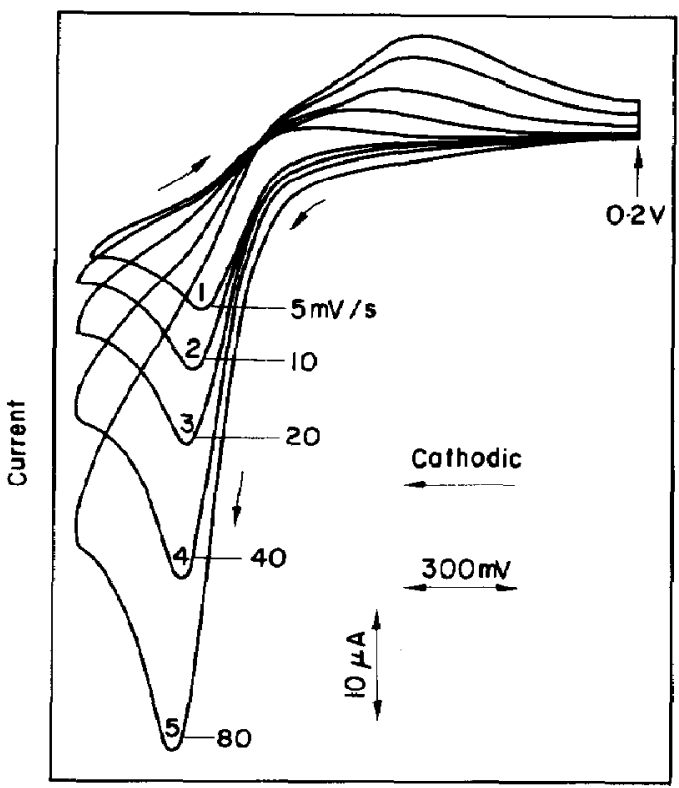

Potential

Fig. 8. Voltagrams obtained at different potential sweep rates. $0 \cdot 004 M \mathrm{NH}_{4} \mathrm{NO}_{3}$ - supporting electrolyte, $44^{\circ} \mathrm{C}$. Reference: sce Pt electrode area $0.13 \mathrm{~cm}^{2}$.

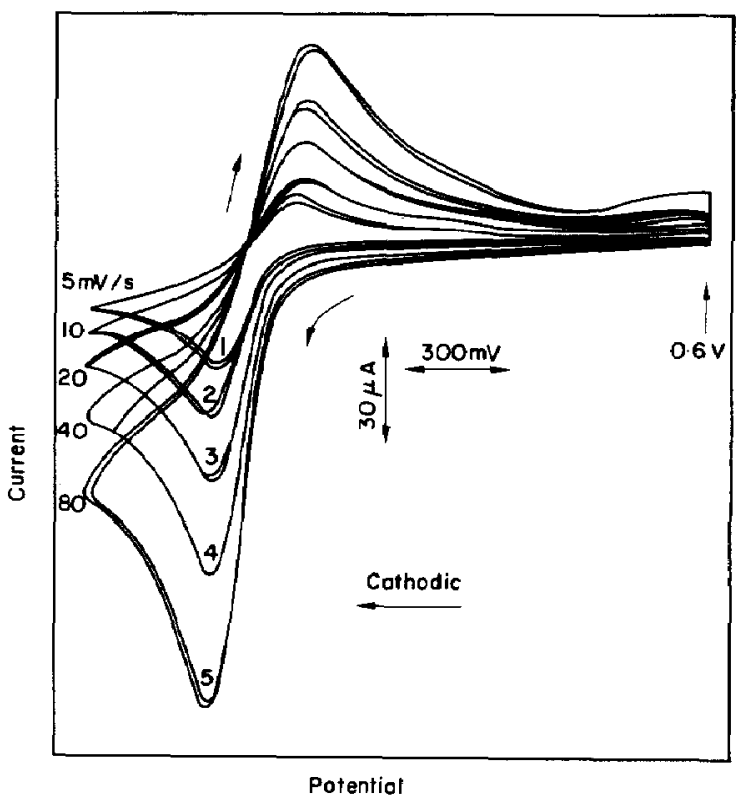

Fig. 9. Voltagrams obtained at different potential sweep rates. $0.0128 \mathrm{M} \mathrm{NH}_{4} \mathrm{NO}_{3}+$ supporting electrolyte, $25^{\circ} \mathrm{C}$. Reference: sce $\mathrm{Pt}$ electrode area $0.13 \mathrm{~cm}^{2}$.

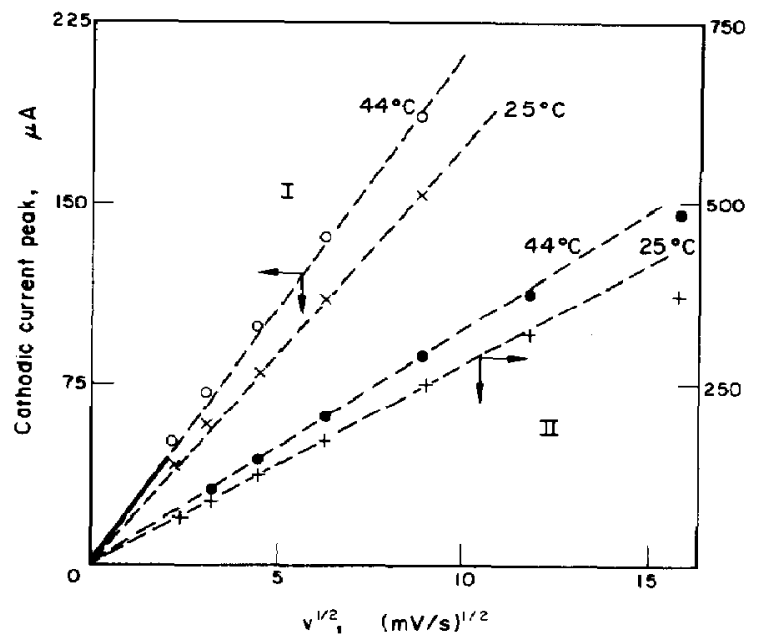

Fig. 10. Dependence of the cathodic current peak on the square root of the potential sweep rate. (I) $0.0013 \mathrm{M}$ $\mathrm{NH}_{4} \mathrm{NO}_{3}+$ supporting electrolyte. Reference: sce Pt electrode area $0.13 \mathrm{~cm}^{2}$. 


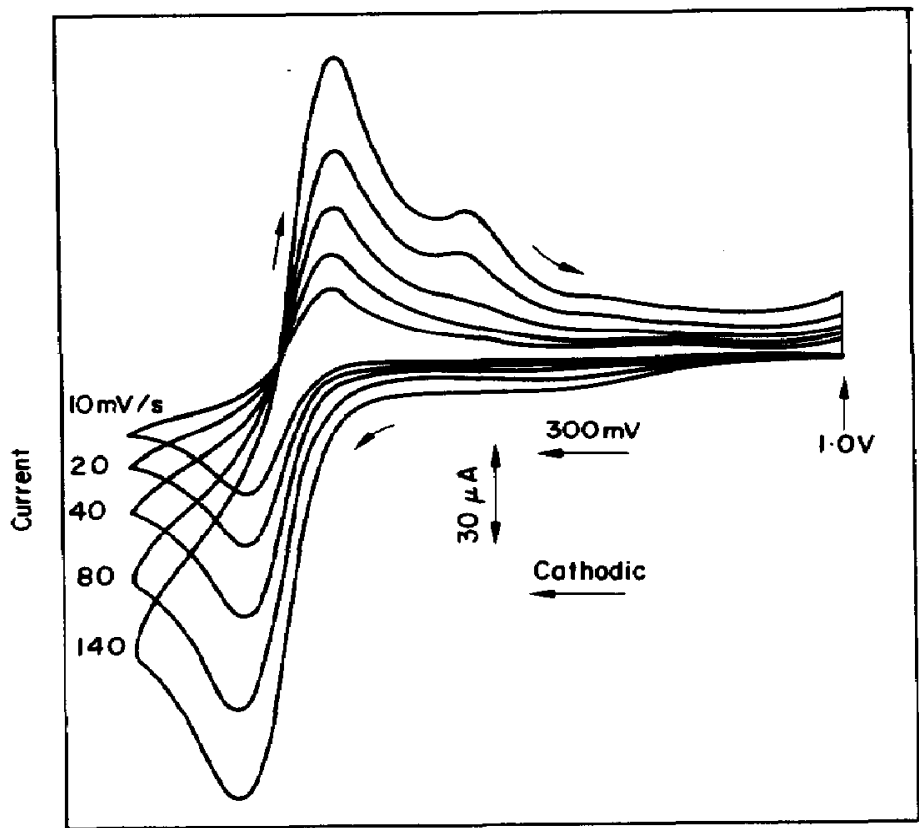

Potentiol

Fig. 11. Voltagrams obtained at different potential sweep rates. $0.013 M \quad \mathrm{NH}_{4} \mathrm{NO}_{3}+$ supporting electrolyte, $25{ }^{\circ} \mathrm{C}$. Reference: sce Pt electrode area $0.13 \mathrm{~cm}^{2}$.

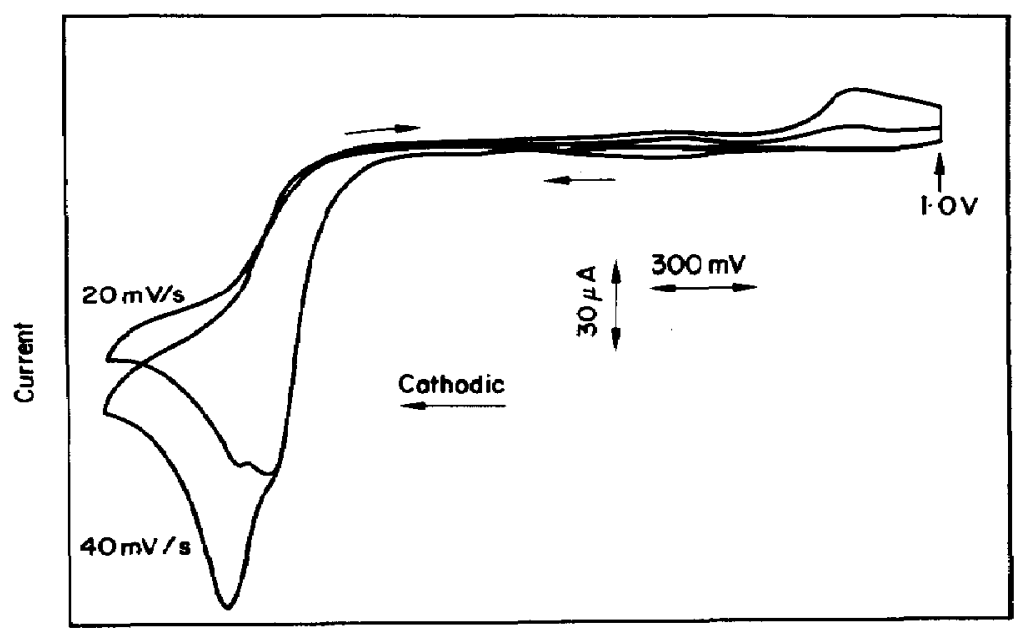

Potential

Fig. 12. Voltagrams obtained at different potential sweep rates on gold $\left(0-13 \mathrm{~cm}^{2}\right) .0 .013 M$ + supporting electrolyte at $25^{\circ} \mathrm{C}$. Reference: sce. 


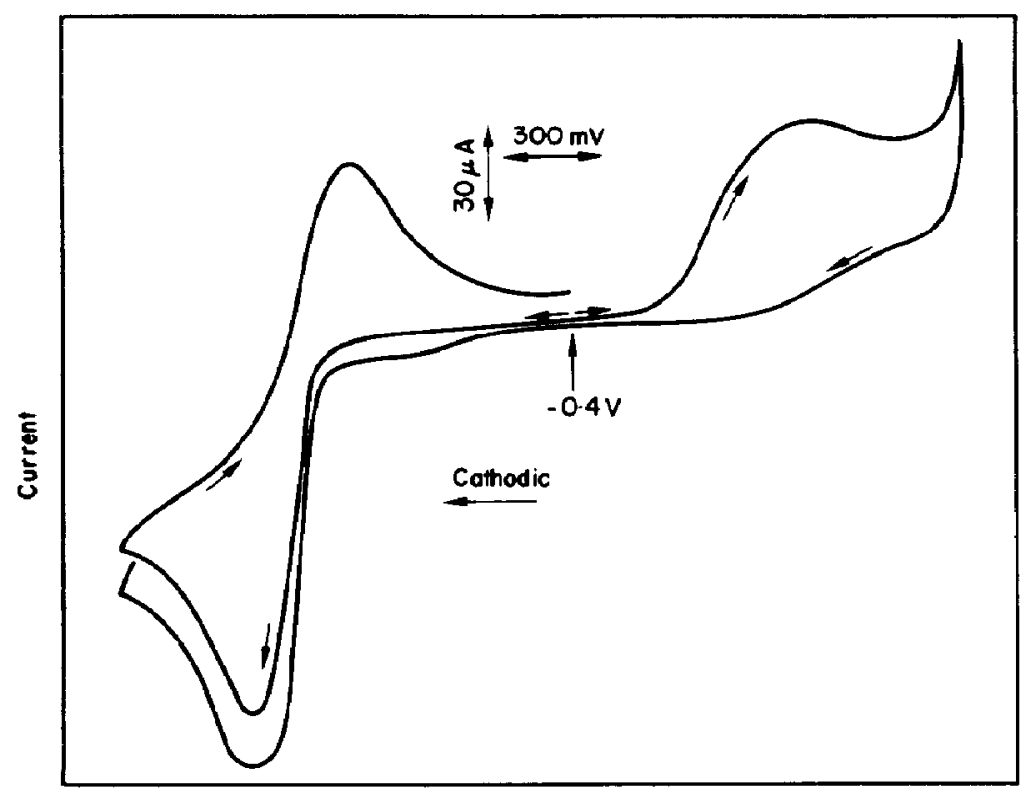

Potential

Fig. 13. Voltagrams obtained at $100 \mathrm{mV} / \mathrm{s}$ on platinum $\left(0-13 \mathrm{~cm}^{2}\right) .0-012 \mathrm{M} \mathrm{NH}_{4} \mathrm{NO}_{3}+0.005 \mathrm{M}$ $\mathrm{NH}_{3}+$ supporting electrolyte. (1) After $30 \mathrm{~min}$ nitrogen bubbling and potential sweep started at $-0.4 \mathrm{~V}$ towards the cathodic region. (2) After $10 \mathrm{~min}$ at rest after previous experiment, and potential sweep started towards the anodic region. Reference $\mathrm{Ag} / \mathrm{Ag}^{+}$(DMSO). Rest potential $-0 \cdot 260 \mathrm{~V}$.

current is observed. The latter decreases after bubbling nitrogen through the solution for a few minutes. Figure 14 shows voltagrams recorded at different potential sweep rates, for a $0-0.0766 \mathrm{M}$ ammonia solution in $1 M$ potassium perchlorate. The height of the anodic current peak changes linearly with the square root of the potential sweep rate and with ammonia concentration, at lower concentrations (Fig. 15). At high ammonia concentration the voltagram exhibits an

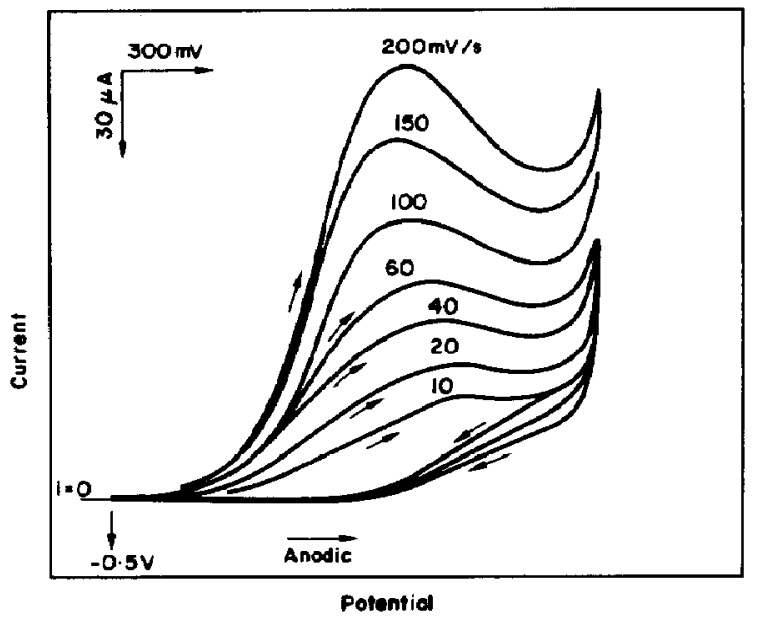

Fig. 14. Voltagrams obtained with a $0.008 \mathrm{M} \mathbf{N H}_{3}+$ supporting electrolyte solution on platinum at different potential sweep rates, $25^{\circ} \mathrm{C}$. Reference $\mathrm{Ag} / \mathrm{Ag}^{+}$(DMSO). anodic limiting current instead of a current peak. The experiments made with ammonia addition suggest that the anodic current peak observed at $+0.8 \mathrm{~V}$ (sce)

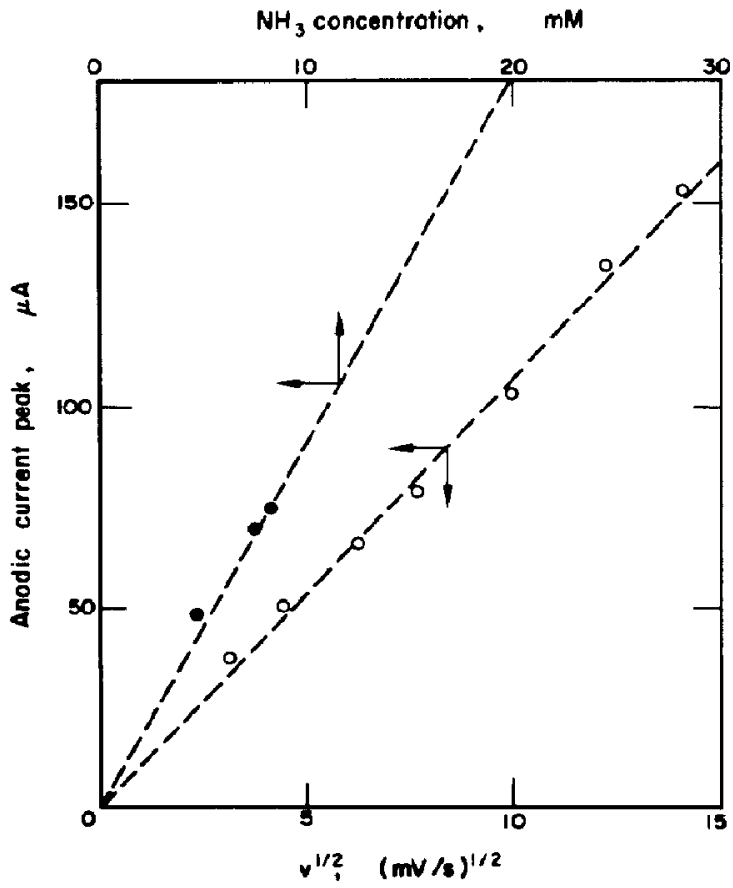

Fig. 15. Dependences of the height of the anodic current peak related to ammonia oxidation, on ammonia concentration and square root of potential sweep rate, $25^{\circ} \mathrm{C}$. 


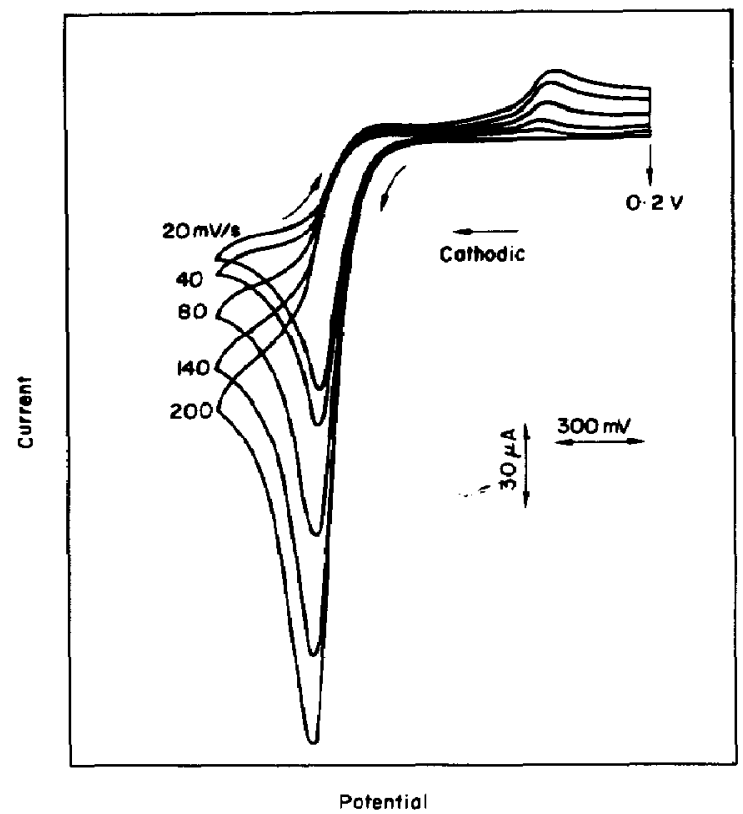

Fig. 16. Voltagrams obtained with a $0.0123 \mathrm{M} \mathrm{HCl}$ solution, at $34.2{ }^{\circ} \mathrm{C}$ on platinum $\left(0.13 \mathrm{~cm}^{2}\right)$, at different potential sweep rates. Reference $\mathrm{Ag} / \mathrm{Ag}^{+}$(DMSO). Rest potential $-0 \cdot 180 \mathrm{~V}$.

(Figs. 13 and 14) corresponds to the electrochemical oxidation of ammonia.

To ascertain any electrochemical oxidation of either molecular or atomic hydrogen, voltagrams of solutions of hydrogen chloride in DMSO were recorded (Fig. 16). A well defined cathodic current peak, corresponding to the discharge of the solvated hydrogen ion was observed. Its height varied also linearly with the square root of the potential sweep rate. In the anodic halfcycle there is a current peak placed at $+0.240 \mathrm{~V}$ (sce), which is probably related to the hydrogen oxidation, if the anodic discharge of the chloride ion is not interfering. Figure 17 shows records obtained at different chloride ion concentrations at potential sweep rates between 20 and $400 \mathrm{mV} / \mathrm{s}$.

The height of the anodic current peak at $c a 0.60 \mathrm{~V}$ increases with both potential sweep rate and halide ion concentration. Consequently, hydrogen electrochemical oxidation occurs within a different potential region than that corresponding to the discharge of the chloride ion. It is thus concluded that the two anodic current peaks appearing between -0.7 and $-0.3 \mathrm{~V}$ (Fig. 11) are probably related to the electrochemical oxidation of hydrogen atoms.

Stationary current-potential curves and currentpotential curves at "zero time"

Figure 18 shows a semilogarithmic plot of galvanostatic current-pctential curves obtained by reading the potential at a certain time starting from the application

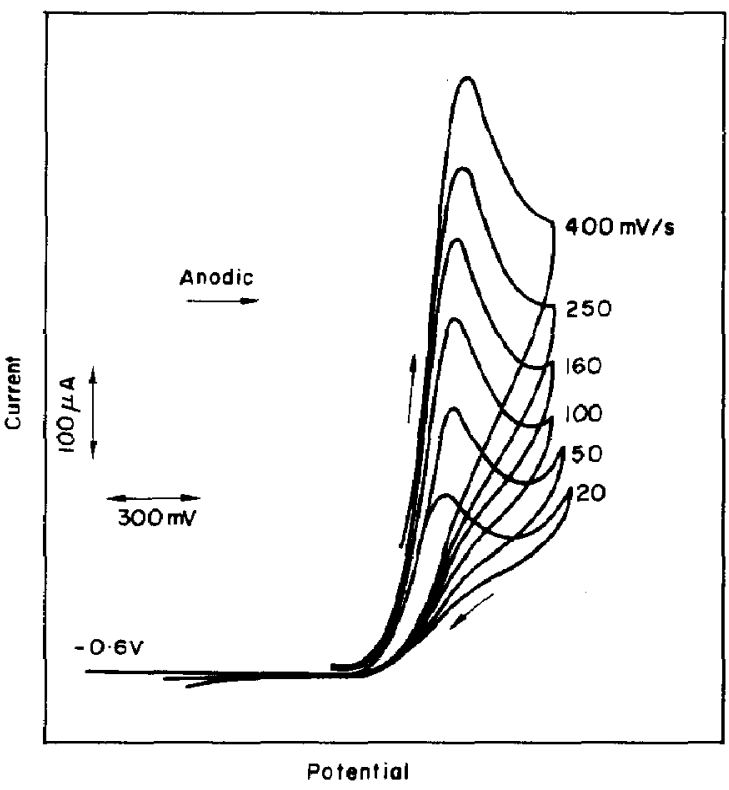

Fig. 17. Voltagrams obtained with a $0.085 \mathrm{M} \mathrm{HCl}+$ supporting electrolyte solution at $34 \cdot 3{ }^{\circ} \mathrm{C}$, on platinum $\left(0.13 \mathrm{~cm}^{2}\right)$ at different potential sweep rates. Reference $\mathrm{Ag} / \mathrm{Ag}^{+}$(DMSO). Rest potential $-0 \cdot 100 \mathrm{~V}$.

of the current pulse. The slope of the Tafel lines increases appreciably with the time elapsing between application of the current pulse and potential readings. A slope of $-120 \mathrm{mV} /$ decade is approaced when this time approaches zero. This suggested plotting currentpotential curves with the extrapolated at $t=0[11]$, from potential-time records (Fig. 19). These plots exhibit slopes of $-125 \mathrm{mV} /$ decade, at $25^{\circ} \mathrm{C}$.

When a constant potential was maintained for a certain time the current stabilized after $30 \mathrm{~min}$. This made it possible to draw current-potential curves at

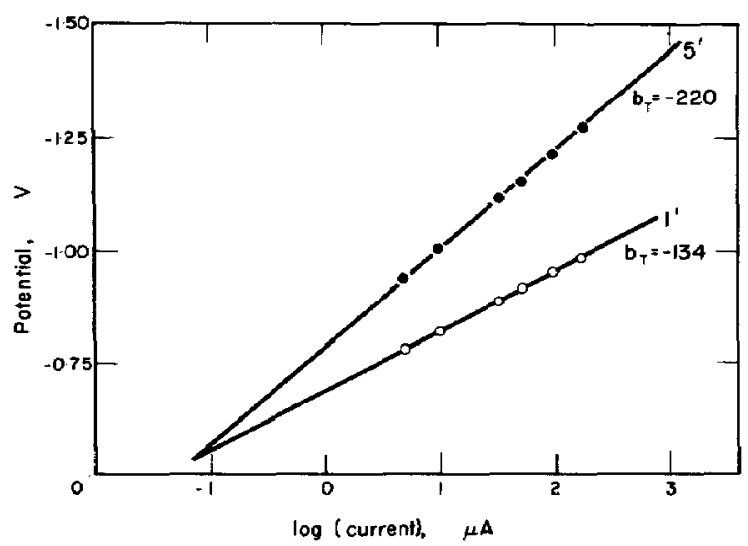

Fig. 18. Tafel plots with data read at different times. $1 M$ $\mathrm{NH}_{4} \mathrm{NO}_{3}$ solution at $25^{\circ} \mathrm{C}$. (O) $1 \mathrm{~min}$, (O) $5 \mathrm{~min}$. The Tafel slopes are indicated in the figure. 


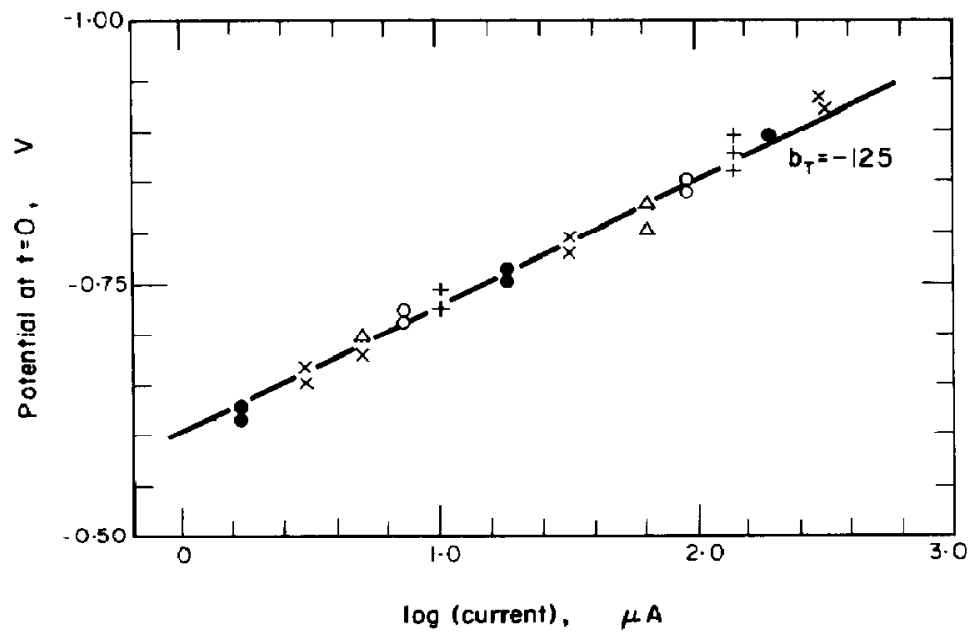

Fig. 19. Tafel plot with galvanostatic data; potential extrapolated at $t=0$. Platinum electrode $\left(0 \cdot 13 \mathrm{~cm}^{2}\right), 25^{\circ} \mathrm{C}$. Tafel slopes are indicated in the figure. Reference $\mathrm{Ag} / \mathrm{Ag}^{+}$(DMSO).

"infinite time". The semilogarithmic plots comprise a Tafel slope close to $-2 \cdot 3(2 R T / F) \mathrm{V} /$ decade (Fig. 20). Within the reproducibility of results, the currentpotential relationship appears as independent of either ammonium ion concentration and ammonia concentration. The apparent activation energy for the cathodic process derived from these plots, within the potential range from -1.00 to $-1.12 \mathrm{~V}$, is $11.5 \pm 2.0$ $\mathrm{kcal} / \mathrm{mole}$. The potential used in any of the Tafel plots just described was corrected for the ohmic overpotential. The pseudo-ohmic resistance was measured in the usual way[12].

The cathodic overpotential decay at current interruption

(a) Experiments with static electrodes. Cathodic overpotential decay curves were obtained with electrodes previously treated as follows: (i) the electrode was immersed for $5 \mathrm{~min}$ into a hot mixture of $3 \mathrm{vol}$ $12 N \mathrm{HCl}+1$ vol $16 \mathrm{~N} \mathrm{HNO}_{3}+4$ vol $\mathrm{H}_{2} \mathrm{O}$; (ii) dipped into $\mathrm{HNO}_{3}$ at $70-80^{\circ} \mathrm{C}$ for $10 \mathrm{~min}$; (iii) washed with distilled water; (iv) immersed for 5 min in DMSO and finally; (v) put into the working solution. After step (i) the platinum surface was partially attacked showing a duller surface. The potential decay curves were recorded after a steady electrolysis current was obtained. From the potentials and currents read at current interruption, Tafel lines were obtained covering a cathodic potential range from the initial rest potential up to $-0.850 \mathrm{~V}$. Decay slopes $\left(b_{d}=\partial \mathrm{E} / \partial \log t\right)$ were comprised between 30 and 35 $\mathrm{mV} /$ decade. Similar results were obtained with electrodes whose treatment started at step (ii). These electrodes always kept the initial brightness.

The accumulation of reaction products, particularly ammonia, had no appreciable effect on the decay curves. The corresponding slopes were between 36 and

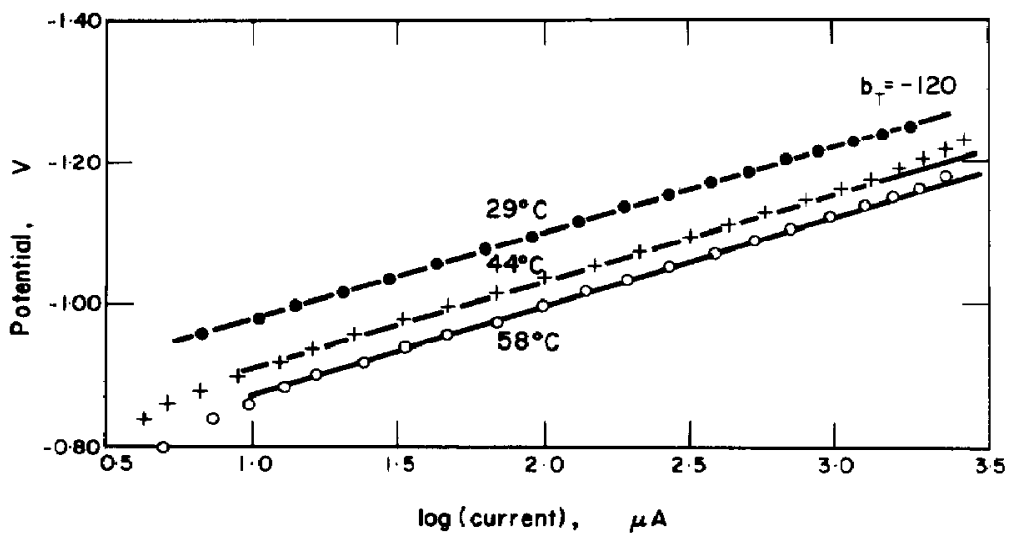

Fig. 20. Tafel plots with galvanostatic data at different temperatures. Platinum electrode $\left(0 \cdot 13 \mathrm{~cm}^{2}\right)$. Readings at $t \quad \infty .1 \cdot 583 \mathrm{M} \mathrm{NH}_{4} \mathrm{NO}_{3}$ solution. Reference $\mathrm{Ag} / \mathrm{Ag}^{+}$(DMSO). 


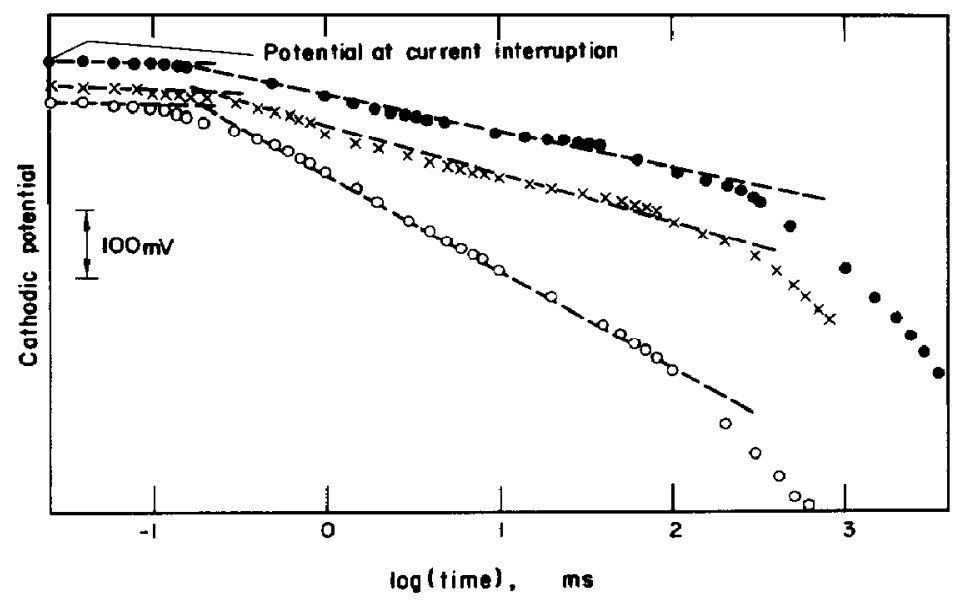

Fig. 21. Semilogarithmic plot of cathodic overvoltage decay curves. Effect of electrolysis time at $253 \mu \mathrm{A}$. Rotating platinum disk electrode at $863 \mathrm{mpm} .1 M \mathrm{NH}_{4} \mathrm{NO}_{3}$ solution at $30{ }^{\circ} \mathrm{C}$. Reference $\mathrm{Ag} / \mathrm{Ag}^{+}$(DMSO). Electrolysis time $(O) 15 \mathrm{~s} ;(\times) 1 \mathrm{~min} ;(O) 10 \mathrm{~min}$.

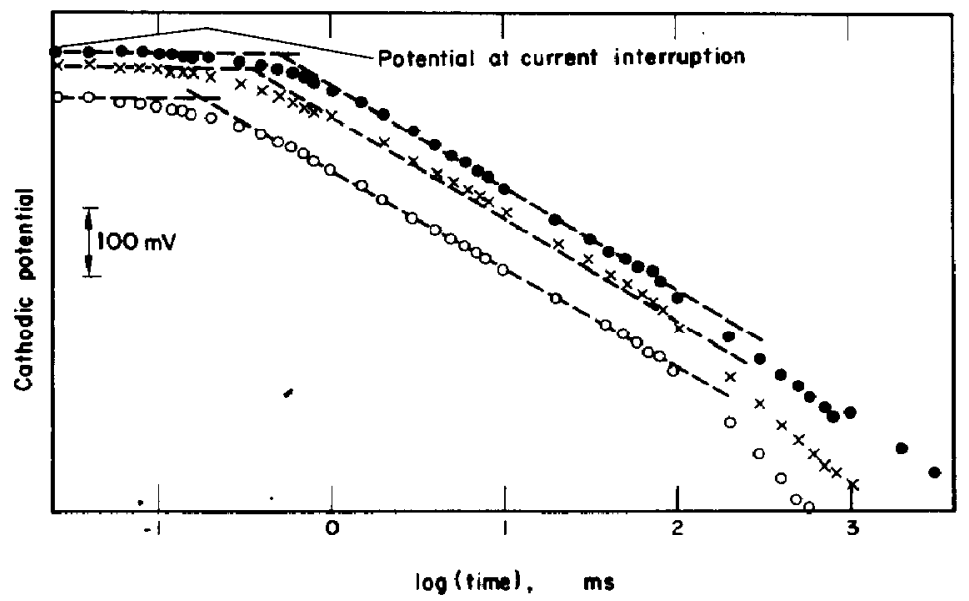

Fig. 22. Semilogarithmic plot of cathodic overvoltage decay curves. Effect of current. Electrolysis time $10 \mathrm{~min}$. Rotating platinum disk electrode $\left(0.07 \mathrm{~cm}^{2}\right)$ at $863 \mathrm{rpm}$. $1 M \mathrm{NH}_{4} \mathrm{NO}_{3}$ solution at $30^{\circ} \mathrm{C}$. Reference Ag/ $\mathrm{Ag}^{+}$(DMSO). (O) $94 ;(x) 170 ;$ (O) $253 \mu \mathrm{A}$.

$40 \mathrm{mV} /$ decade. The apparent electrode capacitance was $9.5 \pm 1.0 \mu F / \mathrm{cm}^{2}$ for electrode treatment (i)-(vii) and $21 \pm 5 \mu F / \mathrm{cm}^{2}$ for treatment (ii)-(vii).

(b) Experiments with rotating disk electrode. These experiments were run with a $1 M$ ammonium nitrate solution changing the rotation speed, the current and the electrolysis time. Semilogarithmic plots of decay curves obtained under different experimental conditions are seen in Figs. 21 and 22. For electrolysis times shorter than 1 min the decay slopes were between $50-80 \mathrm{mV} /$ decade, while at longer times they were of the order of $150 \mathrm{mV} /$ decade under all working conditions, except when the electrode is static. In this case, the slope is $47 \mathrm{mV} /$ decade.

\section{Discussion}

\section{General considerations}

The main process related to the cathodic reduction of ammonium ion dissolved in DMSO on platinum comprises the formation of hydrogen and ammonia. The half-wave potential of the discharge reaction on platinum is much lower than on mercury. For the latter, at $21{ }^{\circ} \mathrm{C}$ it is $-2.13 \mathrm{~V}$ (sce) $[13,14]$, a figure which is close to the half-wave potential for the reduction of potassium ion dissolved in DMSO on the same metal. It was also proved that the polarographic wave of ammonium ion reduction on mercury shows a reversible behaviour. 
The apparent radius of the ammonium ion derived from the $D \eta / T$ ratio ( $\eta$ is the viscosity coefficient), is $1.8 \AA$. When this figure is compared to that of the solvated hydrogen ion $(2 \cdot 3 \AA)[15]$, it is concluded that in DMSO solution the ammonium ion is less solvated than the hydrogen ion. The Stokes radius of the ammonium ion is comparable in size to the radii of potassium, rubidium and caesium ions in DMSO solutions, which are respectively: $2 \cdot 2,2 \cdot 1$ and $1 \cdot 9 \AA[16]$.

The kinetics of the ammonium ion discharge under the present conditions strongly depends on the electrolysis time and on the electrode surface conditions. A preliminary approach to the kinetics of the cathodic process is obtained by chronopotentiometry. The cathodic waves fit the equation for a completely irreversible process[10]:

$$
E=\frac{2 \cdot 3 R T}{\alpha n F} \log \frac{n F C^{\circ} \mathrm{k}_{h}^{\circ}}{i}+\frac{2 \cdot 3 R T}{\alpha n F} \log \left[1-\left(\frac{t}{\tau}\right)^{1 / 2}\right]
$$

where $E$ is the electrode potential at time $t ; n$ is the number of electrons participating in the reaction; $k_{h}^{\circ}$ is the specific rate constant of the cathodic reaction; $\alpha$ is the transfer coefficient assisting the reaction in the cathodic direction and $\tau_{c}$ is the cathodic transition time. Other symbols have the usual meaning. Equation (1) predicts a linear relationship between the potential and the logarithmic term, the slope of which depends on the $\alpha$ value. The best straight lines which fit the results have a $120 \mathrm{mV} /$ decade slope, yielding for $\alpha$ the value 0.5 (Fig. 23). These results also show that the difference between anodic and cathodic half-wave potential increases with current and neither the ratio $\tau_{c} / \tau_{a}$ nor the ratio $\tau_{c} /\left(\tau_{a}+\tau_{a}{ }^{\prime}\right)$ is equal to 3 as should be the case if the oxidation and the reduction processes were complementary.

The potential at "zero time," $E_{t=0}$, extrapolated from the galvanostatic potential/time records, serves to

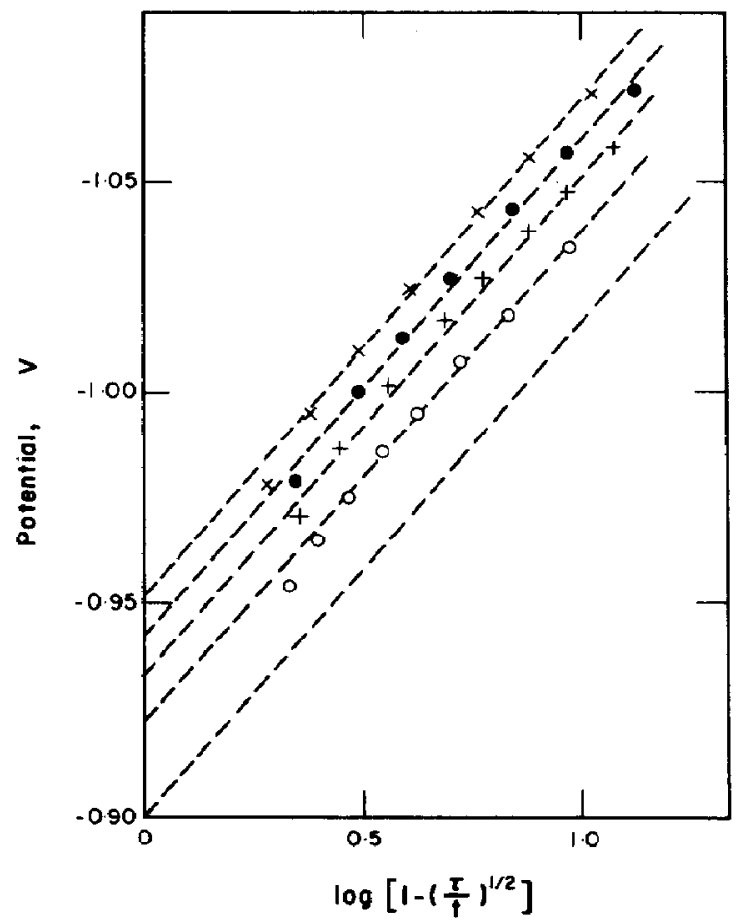

Fig. 23. Potential-time curves at constant current plotted according to (1); $0.013 M \mathrm{NH}_{4} \mathrm{NO}_{3}+1 M \mathrm{KClO}_{4},-25^{\circ} \mathrm{C}$. The slope of dashed line is equal to $2 \cdot 3(2 R T / F) \mathrm{V} /$ decade.

calculate rate constant, $k_{h}^{\circ}$ with equation (1), for $t=0$. Its value, at $44{ }^{\circ} \mathrm{C}$, for a solution containing 1.275 $\times 10^{-2} M \mathrm{NH}_{4} \mathrm{NO}_{3}$ and $1 \mathrm{M} \mathrm{KClO}_{4}$, is $(6.9 \pm 1.6)$ $\times 10^{-12} \mathrm{~cm} / \mathrm{s}$ corresponding to a slow electrochemical reaction. A semilogarithmic $\mathrm{E}_{t=0}$ /current density plot (Fig. 24) yields a straight line with a slope equal to $126 \mathrm{mV} /$ decade at $44{ }^{\circ} \mathrm{C}$ as required for $\alpha=0.50$.

The voltagrams show the occurrence of one main cathodic current peak and at least three important

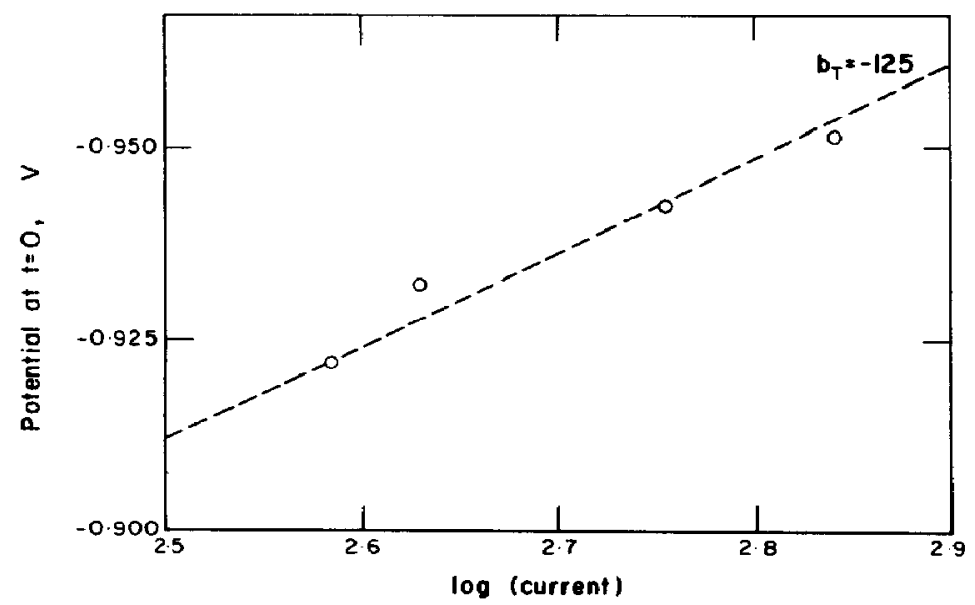

Fig. 24. Tafel plot with potentials read at $t=0.0013 \mathrm{M} \mathrm{NH}_{4} \mathrm{NO}_{3}+$ supporting electrolyte at $44{ }^{\circ} \mathrm{C}$. Electrode area $0.13 \mathrm{~cm}^{2}$. The Tafel slope is indicated in the figure. Reference: sce. 
anodic current peaks. The cathodic peak was interpreted either as a reversible process (with equation 2) or as an irreversible process (with equation 3)[17]

$$
\begin{gathered}
I_{p(\mathrm{rev})}=269 n^{3 / 2} A D^{1 / 2} v^{1 / 2} \mathrm{C}^{0}, \\
I_{P(\mathrm{rrev})}=298 n\left(\alpha n_{a}\right)^{1 / 2} A D^{1 / 2} v^{1 / 2} \mathrm{C}^{0} .
\end{gathered}
$$

Equations (2) and (3) comprise the peak current, $I_{p}$, in $A$; the electrode area, $A$, in $\mathrm{cm}^{2}$; the diffusion coefficient, $D$, in $\mathrm{cm}^{2} / \mathrm{s}$; the potential sweep rate, $v$, in $\mathrm{V} / \mathrm{s}$ and the molar concentration of the ammonium salt, $C^{0}$. In applying (2) or (3), it was supposed that the total number of electrons in the process, $n$, was equal to one, the diffusion coefficient was that calculated from the rotating disk electrode data and the transfer coefficient was equal to $0 \cdot 5$. The comparison of the experimental and calculated data indicates the occurrence of a cathodic irreversible process. On the other hand, the fact that $I_{p}$ is independent of $v^{1 / 2}$, indicates that no cathodic precedent chemical reaction affects the kinetics of the electrode reaction.

The anodic current peak placed at more anodic potentials correspond to the ammonia oxidation, but those anodic current peaks located at more cathodic potentials, are directly related to the oxidation of adsorbed hydrogen on platinum. This derived after comparing the voltagrams obtained with platinum and gold electrodes. Hydrogen anodic peaks are not observed on gold electrodes and the cathodic peak is different from that obtained on platinum. These features of the reaction on gold and platinum electrodes are not surprising; they agree with the observations by Lapteva, Borissova and Slinko[18] and by Breiter[19] for the discharge of the hydrogen ions in aqueous medium. These authors found that when the gold content in a gold-platinum alloy electrode was increased, the quantity of adsorbed hydrogen decreased and when the gold content was more than $40 \%$, the anodic current peaks disappeared, probably because the $d$-electron band of platinum was gradually filled with the increase of gold and consequently, the quantity of adsorbed hydrogen decreased. The place of the anodic current peaks related with the oxidation of adsorbed hydrogen, as well as the potential difference between them, are comparable to what has been reported in the aqueous medium.

The current-potential curves show a hysteresis which is more marked when the current readings at constant potential are made at longer intervals. Then, the reaction clearly becomes more irreversible. This is also reflected in the cathodic potential decay at current interruption, as decay curves are very sensitive to the previous electrode treatment. When the electrode has been recently activated the slope of the cathodic potential decay is of the order of $R T / 2 F$; on the other hand, when the electrolysis is carried out for a long time, reaching a steady condition, a cathodic slope is defined equal to $2 R T / F$; still larger slopes may result with solutions electrolysed for a much longer time. In connection with this, it is to be referred that the values of the experimental differential capacitance of the working electrode is consistent with a simple structure of the electrochemical double layer.

\section{Possible reaction mechanisms without specific adsorption}

The reaction mechanisms which may explain the cathodic reduction of the ammonium ion, should involve ammonia and hydrogen formation as major reaction products. The possible simple reaction pathways are:

\section{Scheme I}

$$
\begin{gathered}
\mathbf{P t}+\mathbf{N H}_{4}^{+}+e=\mathbf{N H}_{3}+\mathbf{P t}(\mathbf{H}) \\
\mathbf{P t}(\mathbf{H})+\mathbf{N H}_{4}^{+}+e=\mathbf{N H}_{3}+\mathbf{H}_{2}+\mathbf{P t} .
\end{gathered}
$$

Scheme II

$$
\begin{aligned}
& \mathrm{Pt}+\mathrm{NH}_{4}^{+}+e=\mathrm{NH}_{3}+\mathrm{Pt}(\mathrm{H}) \\
& \mathrm{Pt}(\mathrm{H})+\mathrm{Pt}(\mathrm{H})=2 \mathrm{Pt}+\mathrm{H}_{2} .
\end{aligned}
$$

Scheme III

$$
\begin{aligned}
\mathbf{P t}+\mathrm{NH}_{4}^{+}+e & =\mathbf{P t}\left(\mathrm{NH}_{4}\right) \\
\mathbf{P t}\left(\mathrm{NH}_{4}\right) & =\mathrm{Pt}(\mathbf{H})+\mathrm{NH}_{3} \\
\mathbf{P t}(\mathbf{H})+\mathrm{Pt}(\mathrm{H}) & =2 \mathbf{P t}+\mathrm{H}_{2} .
\end{aligned}
$$

Scheme IV

$$
\begin{gathered}
\mathbf{P t}+\mathbf{N H}_{4}^{+}+e=\mathbf{P t}\left(\mathrm{NH}_{4}\right) \\
\mathbf{P t}\left(\mathbf{N H}_{4}\right)+\mathbf{N H}_{4}^{+}+e=2 \mathbf{N H}_{3}+\mathbf{H}_{2}+\mathbf{P t} .
\end{gathered}
$$

The parentheses indicate adsorbed intermediate species. The cathodic Tafel slopes derived from the kinetic analysis of Schemes I-IV are similar to those already known for formally similar hydrogen evolution reaction mechanisms.

It is evident that the kinetic data do not allow to conclude about the possible existence of the ammonium radical as reaction intermediate. The formation of an ammonium amalgam was investigated by Johnston and Ubbelohde[20], by electrolysing aqueous solutions of ammonium sulphate on mercury cathodes. These authors claim that for the amalgam formation the ammonium radical gives up one electron to the conduction band of mercury. Polarngraphic experiments seems to confirm the existence of this radical[21], although its average life time during its electrochemical formation may be too short for detection[22]. The average life time of the ammonium radical would be still shorter on platinum than on mercury, because the hydrogen adsorption energy for platinum is larger than for mercury. This fact would shift the following reaction towards the right side:

$$
\operatorname{Pt}\left(\mathrm{NH}_{4}\right)=\mathrm{Pt}(\mathrm{H})+\mathrm{NH}_{3} .
$$

Then, if the average life time of the ammonium radical is short, hydrogen atoms will be the intermediates of actual kinetic significance. Under these conditions 
Table 1. Rate equations derived from reaction schemes $\mathrm{V}$ and VI

\begin{tabular}{|c|c|c|c|}
\hline $\begin{array}{l}\text { Reaction } \\
\text { scheme }\end{array}$ & $r d s$ & Conditions & Rate equation \\
\hline $\mathrm{V}$ & $\mathrm{Vb}$ & L.I. $(\vartheta \rightarrow 0)$ & $i=n F k_{\mathrm{Vb}}{ }^{\circ} C \exp \left[(-\beta \Delta \phi F / R T)\left(1-m \mu / e_{0} \delta\right)\right]$ \\
\hline $\mathrm{V}$ & $\mathrm{Vc}$ & L.I. $(\theta \rightarrow 0)$ & $i=n F k_{\mathrm{v}_{\mathrm{c}}}{ }^{0}\left(K_{\mathrm{Vb}}{ }^{0}\right)^{2}\left(C / C^{\prime}\right)^{2} \exp \left\{(-2 F \Delta \phi / R T)\left[1-(1-\beta)\left(m \mu / e_{0} \delta\right)\right]\right\}$ \\
\hline $\mathrm{v}$ & $\mathrm{Vc}$ & L.I. $(\vartheta \rightarrow 1)$ & $i=n F k_{\mathrm{v}_{\mathrm{c}}}^{0} \exp \left[(-2 \beta F \Delta \phi / R T)\left(m \mu / e_{0} \delta\right)\right]$ \\
\hline V & $\mathrm{Vc}$ & T.I. & $i=n F k_{\mathrm{vc}^{0}}{ }^{0}\left(K_{\mathrm{vb}}{ }^{0}\right)^{2 \beta} \vartheta^{2}\left(C / C^{\prime}\right)^{2 \beta} \exp (-2 \beta F \Delta \phi / R T)$ \\
\hline VI & VIb & L.I. $(\theta \rightarrow 0)$ & $i=n F k_{\mathrm{vIh}}^{0} \exp \left[(-\beta \Delta \phi F / R T)\left(1-m \mu / e_{0} \delta\right)\right]$ \\
\hline VI & VIc & L.I. $(\vartheta \rightarrow 0)$ & $i=n F k_{\mathrm{Vlc}}^{0} K_{\mathrm{vbb}}^{0} C\left(C / C^{\prime}\right) \exp \left[-\left(1+\beta-m \mu / e_{0} \delta+m \beta \mu / e_{0} \delta\right)(F \Delta \phi / R T)\right]$ \\
\hline VI & VIc & I.I. $(9 \rightarrow 1)$ & $i=n F k_{\mathrm{Vlc}}^{0} C \exp \left[(-\beta F \Delta \phi / R T)\left(1+m \mu / e_{0} \delta\right)\right]$ \\
\hline VI & VIc & T.I. & $i=n F k_{\mathrm{Vlk}}^{0}\left(K_{\mathrm{VIt}}^{0}\right)^{\beta} 9 C\left(C / C^{\prime}\right)^{\beta} \exp (-F \Delta \phi / R T)$ \\
\hline
\end{tabular}

L.I. = Langmuir isotherm; T.I. = Temkin isotherm.

reactions schemes III and IV become formally equal to schemes I and II.

Independently of any reaction intermediates any simple reaction pathway involving either Langmuir or Temkin isotherms fails to explain the experimental results satisfactorily. The above described reaction schemes initiates the reaction on a clean platinum surface. This situation, if it actually exists, would appear only as a limiting case at $t \rightarrow 0$.

\section{Possible reaction mechanisms involving specific adsorption}

A more realistic description of the reaction interface would correspond to an electrode surface covered by solvent molecules, in accordance with a distribution function which depends on the potential applied to the interface. At high cathodic potentials it is likely that the dipoles are predominantly ordered with their positive end towards the electrode surface. This can be expressed in terms of the following equilibrium, which under the present conditions is probably shifted towards the right side:

$$
\mathbf{P t}+\mathrm{DMSO}=\mathrm{Pt}(\mathrm{DMSO})_{\mathrm{ads}}
$$

Other possible adsorption processes, which in turn may become important, are:

$$
2 \mathrm{Pt}+\mathbf{H}_{\mathbf{2}}=2 \mathrm{Pt}(\mathrm{H})
$$

and

$$
\mathrm{Pt}+\mathrm{NH}_{3}=\mathbf{P t}\left(\mathrm{NH}_{3}\right) \text {. }
$$

Substances produced in minor quantities, probably as a consequence of the solvent reduction by hydrogen atoms, may also interfere at" the electrode surface according to:

$$
\mathbf{P t}+\mathrm{X}=\mathbf{P t}(\mathrm{X})
$$

where $X$ is any reduction product adsorbed on platinum, probably dimethylsulphide[23].
Water must also be taken into account since it is contained as an impurity in the solvent. Nevertheless, within the water concentration range which is present in the solvent, its influence may be neglected as deduced from electrolyte solution studies with waterDMSO mixtures[24].

The occurrence of any of those reactions modifies the schemes of reaction I and II in the following way:

$$
\begin{aligned}
\text { Scheme V } \\
\mathbf{P t}+\mathbf{P}=\mathbf{P t}(\mathbf{P}) \\
\mathrm{Pt}(\mathbf{P})+\mathrm{NH}_{4}^{+}+e=\mathbf{P t}(\mathbf{H})+\mathrm{NH}_{3}+\mathbf{P} \\
\mathrm{Pt}(\mathrm{H})+\mathrm{Pt}(\mathrm{H})=2 \mathbf{P t}+\mathbf{H}_{2} .
\end{aligned}
$$

Scheme VI

$$
\begin{aligned}
\mathbf{P t}+\mathbf{P} & =\mathbf{P t}(\mathbf{P}) \\
\mathbf{P t}(\mathbf{P})+\mathbf{N H}_{4}^{+}+e & =\mathbf{P t}(\mathbf{H})+\mathbf{N H}_{\mathbf{3}}+\mathbf{P} \\
\mathbf{P t}(\mathbf{H})+\mathbf{N H}_{4}^{+}+e & =\mathbf{P t}+\mathbf{H}_{\mathbf{2}}+\mathbf{N H}_{3} .
\end{aligned}
$$

where $\mathbf{P}$ indicates an adsorbed molecule (solvent, impurity, etc). The kinetic analysis of these reaction schemes can be made in terms of the Bockris model[25] for the adsorption dependence on potential for the $P$ molecules[26]. It can be simplified if it is assumed that the reaction occurs at a potential far from the equilibrium potential. The rate equations derived from this kinetic analysis for the different possible reaction pathways, either under Langmuir or Temkin adsorption, arc assembled in Table $1 . k_{i}^{0}$ is the specific rate constant of step $i$, when the potential difference across the reaction interface, $\Delta \phi$, is equal to zero; $K_{i}{ }^{0}$ is the equilibrium constant of step $i$, at $\Delta \phi=0 ; C$ and $C^{\prime}$ are the ammonium ion and ammonia concentrations respectively, at the reaction interface, which are supposed equal to the corresponding bulk concentrations; $\beta$ is a symmetry factor; $m$ is the number of molecules replaced by each adsorbed intermediate; $\mu$ is the dipole moment of the P molecule; $e_{0}$ is the electron charge and $\delta$ is the thickness of the compact 
Table 2. Cathodic Tafel slopes derived from reaction schemes $\mathrm{V}$ and VI, at $25^{\circ} \mathrm{C}$. $(\beta=0.5)$

\begin{tabular}{|c|c|c|c|c|c|}
\hline $\begin{array}{l}\text { Reaction } \\
\text { scheme }\end{array}$ & $r d s$ & conditions & $b_{T}$ & $\underset{m \mathrm{~V}}{b_{T}(m=1)}$ & $\begin{array}{c}b_{T}(m=2) \\
m V\end{array}$ \\
\hline $\mathrm{v}$ & $\mathrm{Vb}$ & L.I. $(\vartheta \rightarrow 0)$ & $-\frac{2 R T}{F(1-0.265 m)}$ & -163 & -250 \\
\hline $\mathbf{v}$ & $\mathrm{Vc}$ & L.I. $(\vartheta \rightarrow 0)$ & $-\frac{R T}{2 F(1-0.133 m)}$ & $-34 \cdot 5$ & -41 \\
\hline v & Vc & L.I. $(\vartheta \rightarrow 1)$ & $-\frac{R T}{F(0.265 \mathrm{~m})}$ & -223 & -112 \\
\hline VI & VIb & L.I. $(\vartheta \rightarrow 0)$ & $-\frac{2 R T}{F(1-0 \cdot 265 \mathrm{~m})}$ & -163 & -250 \\
\hline VI & VIc & L.I. $(\vartheta \rightarrow 0)$ & $-\frac{R T}{F(1.5-0.133 \mathrm{~m})}$ & -43 & -48 \\
\hline VI & VIc & L.I. $(\vartheta \rightarrow 1)$ & $-\frac{2 R T}{F(1+0 \cdot 265 \mathrm{~m})}$ & -95 & -78 \\
\hline
\end{tabular}

region of the electrical double layer which may be taken as the average diameter of the $P$ molecule on the surface. The values of the Tafel slope indicated in Table 2 were calculated with the following parameters (on assuming the $P$ molecule is either a solvent or a dimethylsulphide molecule)[28]: $\mu=3.9 \times 10^{-8}$ esu $x \mathrm{~cm}, e_{0}=4.8 \times 10^{-10}$ esu and $\delta=3.05 \times 10^{-8} \mathrm{~cm}$, for $m=1$ and $m=2$. For $m=0$, the analysis yields the same constants as those under a simple Langmuir adsorption. The kinetic analysis, under intermediate surface coverages, the reaction intermediates following a Temkin isotherm, yields the Tafel constants already known[27].

The kinetic analysis of the reaction mechanisms involving competitive adsorption can be extended to non-stationary conditions, such as those reported for the cathodic overvoltage decay at current interruption[28]. The potential decay is governed by the differential equation :

$$
i=-C_{e}\left(\frac{\partial \Delta \phi}{\partial t}\right)
$$

where the expression of the faradaic current depends on the mechanism of the reaction. When the electrode differential capacitance is electrode potential independent, (4) can be easily integrated, after replacing the current density by its corresponding expression. Thus, the time dependence of the electrode potential after current interruption is obtained.

Let us consider, as examples, scheme $V$ with different rate determining steps. The following results are obtained:

(i) Step $\mathrm{Vb}$ is $r d s$ under L.I. $(\vartheta \rightarrow 0)$,

$$
\begin{aligned}
\frac{K C t}{C_{e}}+\text { const }=- & \frac{R T}{\beta F}\left(1-\frac{m \mu}{e_{0} \delta}\right)^{-1} \\
& \times \exp \left[\left(\frac{\beta F \Delta \phi}{R T}\right)\left(1-\frac{m \mu}{e_{0} \delta}\right)\right]
\end{aligned}
$$

(ii) Step Ve is $r d s$ under L.I. $(\theta \rightarrow 0)$,

$$
\begin{aligned}
\frac{K^{\prime}\left(C / C^{\prime}\right)^{2} t}{C_{e}} & + \text { const }=-\frac{R T}{2 F}\left[1-\frac{m \mu}{e_{0} \delta}(1-\beta)\right]^{-1} \\
& \times \exp \left[\left(\frac{2 F \Delta \phi}{R T}\right)\left(1-\frac{m \mu}{e_{0} \delta}(1-\beta)\right)\right] .
\end{aligned}
$$

(iii) Step Vc is $r d s$ under L.I. $(\theta \rightarrow 1)$,

$$
\frac{K^{\prime \prime} t}{C_{e}}+\text { const }=-\frac{R T e_{0} \delta}{m \mu F} \exp \left(\frac{m \mu}{e_{0} \delta} \frac{F \Delta \phi}{R T}\right) .
$$

The constants $K, K^{\prime}$ and $K^{\prime \prime}$ contains all the terms which are in the pre-exponential factors and are potential independent. Equations (5-7), the latter for $m \neq 0$, give a linear relationship between $\Delta \phi$ and $\log t$, the decay slope of the straight line being equal to those already established for the same mechanism under stationary conditions.

Therefore, from the comparison of the experimental Tafel and decay slopes with the theoretical ones and from the dependence of the cathodic current density, at constant $\Delta \phi$, on the $(C / C)$ ratio, it is concluded that among the various mechanisms discussed above, the scheme $V$ with step Vc as rate determining and $m=2$ explains most of the kinetic parameters of the electrochemical reduction of the ammonium ion dissolved in DMSO on platinum. The participation of adsorption process explains the low Tafel slopes, of the order 
of $-40 \mathrm{mV}$, as well as the slopes larger than -120 $\mathrm{mV}$ at $25^{\circ} \mathrm{C}$. The latter appear always related to a high degree of surface coverage. When the system is electrolyzed for a long time before kinetic measurements are initiated a high and constant degree of surface coverage is reached, a situation which is more rapidly attained with the moving electrodes.

The mechanism of the cathodic reduction of the ammonium ion in DMSO on platinum shows a formal similarity with that of the reduction of the solvated proton on DMSO on platinum, as earlier reported $[10,28,29]$. The oxidation of the reaction products, adsorbed hydrogen and ammonia also occurs, as indicated by cyclic voltammetry. The former is similar to that observed for the hydrogen electrode reaction on platinum. The two oxidation current peaks of adsorbed hydrogen are explained on the basis of reaction $\mathrm{Vb}$, where the charge transfer would not require the presence of ammonia at the interface. The existence of two oxidation peaks would mean the existence of two energetic states for the adsorbed hydrogen on platinum[19]. The second oxidation current peak placed at more anodic potentials belongs to the highest adsorption energy state, and correspondingly this current peak increases strongly with temperature. The oxidation current peak, related to ammonia also corresponds to an irreversible process, the overall reaction probably yielding ammonium ion as a final product. This reaction in particular is being studied in detail and results will be reported in the near future.

Acknowledgement-This work is part of the research program of I.N.I.F.T.A., which is sponsored by the Universidad Nacional de La Plata, Consejo Nacional de Investigaciones Científicas y Técnicas and Comisión de Investigaciones Científicas de la Provincia de Buenos Aires. Lic. C. Martínez thanks the Universidad Nacional de Tucumán for the leave of absence and fellowship granted during 1969-1971 and Dr. J. A. Wargon acknowledges the fellowship granted by the C.O.N.I.C.E.T.

\section{REFERENCES}

1. A. J. Arvia, M. C. Giordano and J. J. Podestá, Electrochim. Acta 14, 389 (1969).

2. V. Macagno, M. C. Giordano and A. J. Arvia, Electrochim. Acta 14, 335 (1969).
3. D. Posadas, A. J. Arvía and J. J. Podestá, Electrochim. Acta 16, 1025 (1971).

4. D. Posadas, A. J. Arvía and J. J. Podestá, Electrochim. Acta 16, 1041 (1971).

5. J. N. Butler, J. Electroanal. Chem. 14, 89 (1967).

6. D. Martin, A. Weis and H. J. Niclas, Angew. Chem. 79,340 (1967).

7. M. E. Martins, G. Paús, A. J. Calandra and A. J. Arvía, An. Asoc. quím. Argent. 57, 91 (1969).

8. G. Paús, A. J. Calandra and A. J. Arvia, An. Soc. cient. Argent. 192, 35 (1971).

9. A. J. Arvía and S. L. Marchiano, Modern Aspects of Electrochemistry, (Edited by J. O'M. Bockris), Vol. 6, Plenum Press, New York (1971).

10. P. Delahay, New Instrumental Methods in Electrochemistry, Interscience New York (1966).

11. K. J. Vetter, Electrochemical Kinetics, p. 412, Academic Press, New York (1967).

12. A. J. Arvía, A. J. Calandra and H. A. Videla, Electrochim. Acta 13, 167 (1968).

13. V. Gutmann and G. Schoeber, Z. analyt. Chem. 5, 339 (1959).

14. D. L. McMasters, R. B. Dunlap, J. R. Kuempel, L. W. Kreider and T. R. Shearer, Anal. Chem. 39, 103 (1967).

15. J. A. Olabe and A. J. Arvia, Electrochim. Acta 14, 785 (1969).

16. J. A. Bolzan, M. C. Giordano and A. J. Arvía, An. Asoc. quím. Argent, 54, 17 (1966).

17. R. S. Nicholson and I. Shain, Analyt. Chem. 36, 706 (1964).

18. K. A. Lapteva, T. I. Borissova and M. G. Slinko, $Z h$. Fiz. Khim. 30, 61 (1956).

19. M. W. Breiter, Trans. Faraday Soc. 61, 749 (1965).

20. R. J. Johnston and A. R. Ubbelohde, J. chem. Soc. (London) 1731 (1951).

21. B. C. Southworth, R. Osteryoung, K. D. Fleischer and F. C. Nachod, Analyt. Chem. 33, 208 (1961).

22. J. K. S. Wan, J. chem. Educ. 45, 40 (1968).

23. T. C. Franklin and H. Kagawa, Electrochim. Acta 17, 1213 (1972).

24. M. Le Démezet, Bull. Soc. chim. Fr. 4550 (1970).

25. B. B. Damaskin and A. N. Frumkin, Reactions of Molecules at Electrodes, (Edited by N. S. Hush), p. 16, Wiley-Interscience, London (1971).

26. E. Gileadi and G. E. Stoner, J. electrochem. Soc. 118, 1316 (1971).

27. C. Martinez, A. J. Arvia and J. A. Wargon, An. Soc. cient. Argent., 194, 135 (1972).

28. A. J. Arvía, An. Asoc. quim. Argent., 60, 385 (1972).

29. J. A. Olabe and A. J. Arvia, Electrochim. Acta 15, 1685 (1970). 